\title{
AVALIAÇÃO FISICO-QUIMICA E MICROBIANA DE MÉIS COMERCIAIS DA GRANDE DOURADOS - MS
}

\author{
E. MORA JUNIOR ${ }^{1}$, M. S. M. SANTOS ${ }^{2}$, E. M. SILVA ${ }^{3}$ e M. BATISTOTE ${ }^{4}$ \\ ${ }^{1}$ Universidade Estadual de Mato Grosso do Sul, Discente de Ciências Biológicas. \\ ${ }^{2}$ Universidade Estadual de Mato Grosso do Sul, Discente do Programa de Pós-Graduação em \\ Recursos Naturais - PGRN / Laboratório de Biotecnologia, Bioquímica e Biotransformação. \\ ${ }^{3}$ Universidade Estadual de Mato Grosso do Sul, Docente de Ciências Biológicas. \\ ${ }^{4}$ Universidade Estadual de Mato Grosso do Sul, Docentes do Programa de Pós-Graduação \\ em Recursos Naturais - PGRN.
}

E-mail para contato: emjtk13@gmail.com

\begin{abstract}
RESUMO - O mel é produzido por abelhas melíferas a partir de néctar floral, sendo utilizado como alimento in natura e em compostos alimentares. Para tanto, deve atender os padrões de qualidade que asseguram seu caráter benéfico como fonte de nutrientes. $\mathrm{O}$ mel não é um produto estéril, entretanto, não favorece o desenvolvimento de microrganismos que possam estar nele contidos. Esses microrganismos podem ser advindos de fontes naturais primárias e secundárias e, geralmente, se mantêm viáveis sob forma de esporos podendo germinar e se desenvolver deteriorando o produto e causando infecções. Com isso, este estudo visou avaliar méis comerciais da região da grande Dourados - MS em relação à sua microbiota, por meio da quantificação de bactérias, leveduras e bolores, bem como aos parâmetros físico-químicos, tais como $\mathrm{pH}$, acidez, açúcares redutores e sacarose aparente. As características físico-químicas avaliadas neste estudo estiveram em conformidade com a legislação brasileira. A microbiota dos méis analisados apresentou maior quantidade de esporos de mesófilos.
\end{abstract}

\section{INTRODUÇÃO}

O mel é um produto natural apropriado ao consumo in natura e se diferencia na composição química, nas características físicas e organolépticas como cor e aroma. Isso porque depende da espécie da abelha melífera, do clima, da estação do ano bem como de outros fatores antrópicos (TAORMINA et al., 2001; CAMPOS et al., 2003) havendo, assim, uma grande variedade de méis. Este produto natural é utilizado como ingrediente pelas indústrias alimentícias sendo empregado, também, na produção de fármacos e de cosméticos. Para tanto, deve atender a critérios de qualidade estabelecidos oficialmente que, no Brasil, se pautam na Instrução Normativa $\mathrm{n}^{\mathrm{o}} 11$ (IN11/2000), do Ministério da Agricultura, Pecuária e Abastecimento - MAPA (BRASIL, 2000), que informa sobre os limites relativos aos parâmetros físico-químicos, mas não quanto ao conteúdo microbiano. 
O estado de Mato Grosso do Sul desponta, neste segmento do agronegócio, como um potencial produtor de mel, visto que se apresentou em $10^{\circ}$ lugar com uma produção de 821 toneladas, de acordo com dados do Instituto Brasileiro de Geografia e Estatística (IBGE, 2012), entretanto, a produção é menor que a demanda. Segundo a APACAME (2002), este estado possui boas perspectivas quanto à exploração apícola principalmente nas regiões de matas ao sul do estado, nas regiões de cerrado e no pantanal.

De acordo com Campos et al. (2003), o mel é um substrato que não favorece o desenvolvimento de microrganismos devido ao seu elevado conteúdo de açúcares, frutose e glicose que propiciam alta pressão osmótica e a outras propriedades que promovem a formação de peróxido de hidrogênio, além da baixa atividade de água, presença de compostos fenólicos e a outros fatores desconhecidos (TAORMINA et al., 2001).

Entretanto, pode ocorrer a existência de esporos que geralmente são de origem bacteriana, micótica leveduriforme e micótica filamentosa, sendo considerados como de fonte primária se estiveram presentes na fonte de néctar, nos grãos de pólen, na colmeia, na superfície externa das abelhas ou no seu aparelho digestório, ou de fonte secundária, quando incorporados ao produto por ocasião da coleta e envase, provenientes da atmosfera ambiente, poeira, dos manipuladores, dos equipamentos e utensílios contaminados (SNOWDON; CLIVER, 1996; OLAITAN et al., 2007). Por exemplo, esporos de Bacillus cereus são hidrófobos e têm forte aderência às superfícies de aço inoxidável e de diversos materiais, resistindo aos procedimentos de limpeza (ARAÚJO et al., 2009).

Ademais, a qualidade do mel como alimento pode ser aferida mediante os parâmetros físico-químicos como o $\mathrm{pH}$, os sólidos insolúveis, minerais, a atividade de água, acidez, umidade, os açúcares redutores, a sacarose aparente, atividade diastásica $\mathrm{e}$ hidroximetilfurfural. Além de outros parâmetros que incluem a condutividade elétrica, as reações de Lund, de Lugol, de Fiehe e de Xarope de Amido de Milho Hidrolisado (BRASIL, 2000; BOGDANOV et al., 2001). Estas características são fundamentais na físcalização e controle de qualidade dos méis comercializados, garantindo a possibilidade de descobrir se o produto foi ou não adulterado. Neste contexto, este estudo visou realizar um levantamento do percentual de mel produzido em cada região do Brasil, bem como analisar parâmetros físicoquímicos e microbiológicos de méis comerciais da região da grande Dourados - MS.

\section{METODOLOGIA}

\subsection{Levantamento da produção de mel em regiões do Brasil}

Foi realizada uma pesquisa exploratória quantitativa composta por um levantamento bibliográfico em periódicos, artigos e em base de dados cadastrais e estatísticos, no intuito de buscar dados referentes a produtividade do mel no Brasil por região.

\subsection{Análises de pH}

Foi preparada uma suspensão de $10 \mathrm{~g}$ de mel em $50 \mathrm{~mL}$ de água destilada $\left(\mathrm{m} \cdot \mathrm{v}^{-1}\right) \mathrm{e}$ realizada a leitura em pHmetro digital de bancada (ZENEBON et al., 2008). 


\subsection{Determinação de açúcares redutores}

Foram pesadas $2 \mathrm{~g}$ da amostra de mel, sendo dissolvida em água destilada (200 mL) em balão volumétrico. Pipetou-se $50 \mathrm{~mL}$ desta solução para um balão volumétrico de $100 \mathrm{~mL}$ e o volume foi completado com água destilada e, $5 \mathrm{~mL}$ da solução de Fehling A e $5 \mathrm{~mL}$ da solução de Fehling B foram pipetados para um balão de fundo chato de $250 \mathrm{~mL}$, no qual foi adicionado $7 \mathrm{~mL}$ de água e $15 \mathrm{~mL}$ da solução de mel diluída. A mistura foi aquecida e mantida em ebulição por 2 min e $1 \mathrm{~mL}$ da solução de azul de metileno foi utilizado para a titulação, segundo a metodologia (ZENEBON et al., 2008).

\subsection{Determinação de sacarose aparente}

Foi pipetado $50 \mathrm{~mL}$ da solução de mel para um balão volumétrico de $100 \mathrm{~mL}$ e adicionado $25 \mathrm{~mL}$ de água, e a solução foi aquecida em banho-maria a $65^{\circ} \mathrm{C}$. Este frasco foi removido do banho e $10 \mathrm{~mL}$ de solução de ácido clorídrico a $5 \mathrm{M}$ foi adicionado e posteriormente neutralizado com uma solução de hidróxido de sódio a $5 \mathrm{M}$ sendo aferido com papel indicador de $\mathrm{pH}$, o volume foi completado com água e após foram realizadas as análises, conforme Zenebon et al. (2008).

\subsection{Determinação de acidez}

Para determinar a acidez $10 \mathrm{~g}$ de amostra de mel foi colocada em um béquer de $250 \mathrm{~mL}$ e dissolvida em $75 \mathrm{~mL}$ de água. Em seguida, o $\mathrm{pH}$ foi verificado. Seguiu-se a análise realizada por titulação potenciométrica, de acordo com método padronizado constante em Zenebon et al. (2008).

\subsection{Quantificação de microrganismos}

Uma suspensão com $10 \mathrm{~g}$ de mel em $10 \mathrm{~mL}$ de solução salina peptonada a $1 \%$ foi preparada e foi feita diluição seriada até $10^{-2}$ em solução salina com peptona a $0,1 \%$. De cada diluição $0,1 \mathrm{~mL}$ foi espalhada em placa de Petri contendo meio Ágar Batata Dextrose (BDA) com $\mathrm{pH} 5,3$ pela técnica pour-plate. As placas foram incubadas em estufa a $32^{\circ} \mathrm{C}$, por 7 dias. A contagem de Unidades Formadoras de Colônias (UFC. $\mathrm{g}^{-1}$ ) foi realizada macroscopicamente. Colônias de bactérias e de leveduras foram distinguidas mediante preparo de lâminas e observação microscópica (SILVA et al., 2007).

Para a avaliação de esporos de mesófilos aeróbios, foram diluídos $10 \mathrm{~g}$ de mel em 90 $\mathrm{mL}$ de solução salina peptonada estéril, e os volumes de $10 \mathrm{~mL}, 1 \mathrm{~mL}$ e $0,1 \mathrm{~mL}$ de mel foram inoculados em frascos de vidro contendo $100 \mathrm{~mL}$ de Ágar Triptona Glicose Extrato de Levedura (TGE), pH 7,0, previamente fundido e resfriado $50-55^{\circ} \mathrm{C}$. O meio inoculado foi homogeneizado e submetido a choque térmico por $10 \mathrm{~min}$ a $80^{\circ} \mathrm{C}$ em banho-maria para matar as células vegetativas. Após este procedimento, o meio TGE inoculado foi distribuído em cinco placas de Petri e incubado a $30^{\circ} \mathrm{C}$ por $48 \mathrm{~h}$. Procedeu-se, então, à contagem de Unidades Formadoras de Colônias (UFC), sendo o resultado expresso em esporos/g (SILVA et al., 2007). 


\section{RESULTADOS E DISCUSSÃO}

A Figura 1 apresenta a produção média de mel no Brasil por região. Nota-se que a região Sul do país despontou como maior produtora com $49 \%$ enquanto que a região Norte apareceu com 3\% da produção. Ainda que a região Centro-Oeste tenha tido pouca representatividade na produção nacional, $5 \%$, reúne requisitos favoráveis ao desenvolvimento da atividade apícola (CASADO; VIEIRA, 2011).

Figura 1 - Produção de mel por região no Brasil.

Fonte: IBGE (2012).

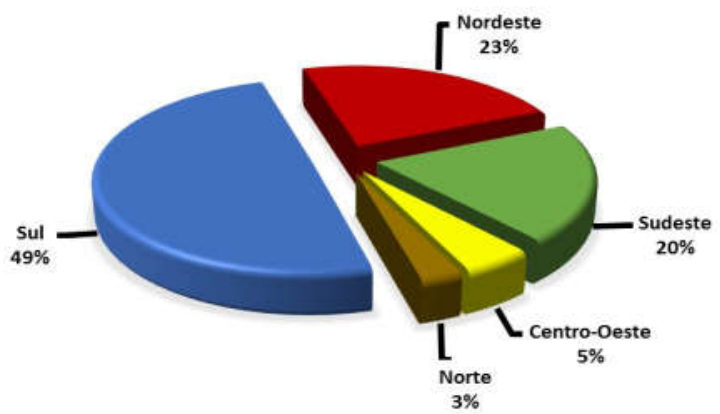

$\mathrm{Na}$ Tabela 1 estão apresentados os dados referentes às análises físico-químicas das amostras de méis da região da Grande Dourados/MS, pode-se observar que os dados obtidos $\mathrm{pH}$, acidez e sacarose aparente estão dentro das especificações técnicas vigentes na Normativa $n^{\circ} 11$, de 20 de outubro de 2000. Segundo Casado e Vieira (2011), em seus estudos de comparação de 25 amostras de méis da região de Chapadão do Sul - MS, as quais foram analisadas quanto ao $\mathrm{pH}$ e acidez, encontraram resultados médios de 4,13 e 40,06 $\mathrm{mEq} / \mathrm{kg}$, respectivamente. Podemos observar, que neste estudo, o valor de $\mathrm{pH}$ foi de $4,11 \mathrm{e}$ acidez de $37,7 \mathrm{mEq} / \mathrm{kg}$ o que denota que os méis sul mato-grossense apresentam um perfil de acidez e pH muito próximos aos relatos da literatura e estão condizentes com a legislação brasileira.

Tabela 1 - Análises físico-químicas das amostras de mel.

\begin{tabular}{|c|c|c|c|c|}
\hline Amostra & pH & $\begin{array}{c}\text { Acidez } \\
(\mathrm{mEq} / \mathrm{kg})\end{array}$ & $\begin{array}{c}\text { Açúcares redutores } \\
\left({\left.\mathrm{g} .100 \mathrm{~g}^{-1}\right)}^{-1}\right.\end{array}$ & $\begin{array}{c}\text { Sacarose aparente } \\
\left(\mathrm{g} .100 \mathrm{~g}^{-1}\right)\end{array}$ \\
\hline $\mathbf{A}$ & 4,39 & 41,90 & 66,34 & 0,25 \\
\hline B & 4,05 & 30,37 & 65,79 & 0,46 \\
\hline $\mathbf{C}$ & 4,02 & 39,89 & 66,47 & 0,01 \\
\hline D & 4,08 & 35,65 & 66,38 & 0,19 \\
\hline Norma vigente $(*)$ & $3,3-3,6$ & Máximo 50 mEq/kg & Mínimo 65 g/100 g & Máximo 6 g/100 g \\
\hline
\end{tabular}

Fonte: Elaborada pelos autores; (*) Valores de referência conforme norma vigente (BRASIL, 2000).

$\mathrm{Na}$ quantificação da microbiota das amostras de méis, os dados mostram uma diversidade de microrganismos, pode-se observar que a amostra $\mathrm{A}$ apresentou bactérias 17

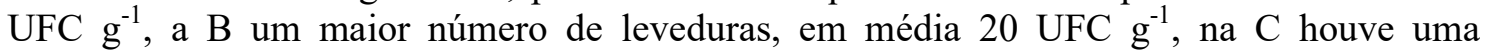


codominância de bactérias e bolores e na $\mathrm{D}$ a ocorrência de bolores. Na análise de esporos, a amostra A continha a menor incidência, 3,4 UFC $\mathrm{g}^{-1}$, enquanto a $\mathrm{B}$ apresentou uma quantidade maior, $36 \mathrm{UFC} \mathrm{g}^{-1}$ (Figura 2).

As bactérias esporuladas mais pesquisadas em mel são do gênero Clostridium, que é anaeróbio estrito. Contudo, existem poucas informações sobre bactérias esporuladas mesófilas aeróbias, como o gênero Bacillus, que tem espécies associadas a alimentos. As espécies $B$. anthracis e $B$. cereus se destacam por causarem, respectivamente, infecção natural ou experimental como arma biológica, e intoxicação alimentar por colonização do intestino delgado. $\mathrm{O} B$. cereus produz enterotoxina e cresce causando no ser humano a síndrome diarreica e emética (SILVA et al., 2007).

Por conter concentração elevada de açúcares, o mel favorece o crescimento de leveduras, que também podem provocar sua deterioração, por meio da produção de enzimas, toxinas, conversão metabólica do alimento, inibição de competidores, tornando o produto não adequado ao consumo. Quanto aos fungos, se apresentarem crescimento em taxas elevadas, levarão à deterioração dos alimentos e por isso são considerados um perigo à saúde pública (FRANCO; LANDGRAF, 2008) devido, por exemplo, a produção de micotoxinas (SILVA et al., 2007).

Figura 2 - Avaliação da microbiota de méis da região da Grande Dourados.

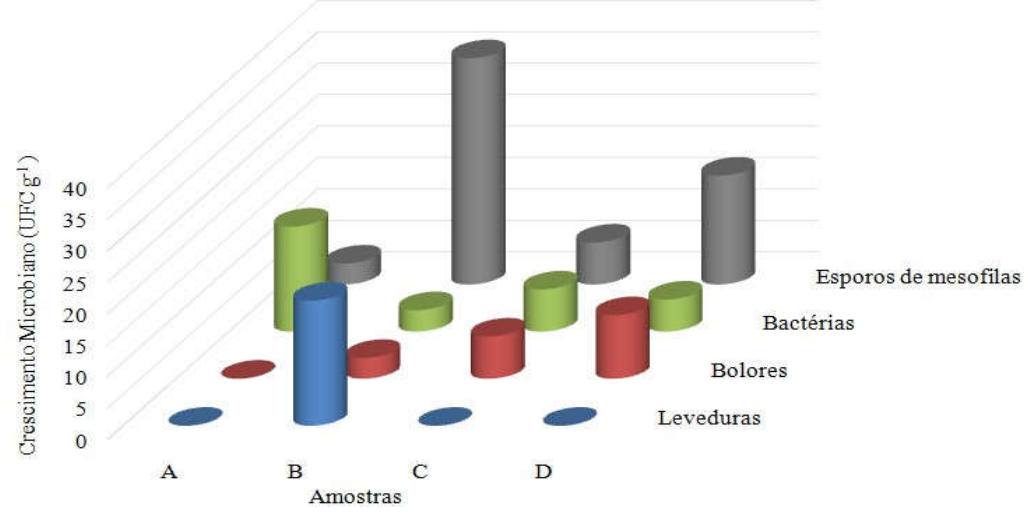

\section{CONCLUSÃO}

As características físico-químicas avaliadas neste estudo estiveram de acordo com a da Instrução Normativa $\mathrm{n}^{\circ} 11$, de 20 de outubro de 2000. A microbiota dos méis analisados apresentou maior quantidade de esporos mesófilos.

\section{REFERÊNCIAS}

APACAME-ASSOCIAÇÃO PAULISTA DE APICULTORES CRIADORES DE ABELHAS MELÍFICAS EUROPÉIAS. Apicultura no Mato Grosso do Sul. Mensagem Doce. São Paulo, n.67, 2002. Disponível em: http://www.apacame.org.br/mensagemdoce/67/comentario.htm. Acesso em 25 março de 2017. 
ARAÚJO, E. A.; BERNARDES, P. C.; ANDRADE, N. J.; FERNANDES, P. E.; SÁ, J. P. N. Hidrofobicidade de ribotipos de Bacillus cereus isolados de indústria de laticínios. Alim. Nutr., Araraquara v.20, n.3, p. 491-497, jul./set. 2009.

BOGDANOV, S.; LÜLLMANN, C.; MARTIN, P.; VON DER OHE, W.; RUSSMANN, H.; VORWOHL, G.; ODDO, L. P.; SABATINI, A. G.; MARCAZZAN, G. L.; PIRO, R.; FLAMINI, C.; MORLOT, M.; LHÉRITIER, J.; BORNECK; R.; MARIOLEAS, P.; TSIGOURI; A.; KERKVLIET, J.; ORTIZ, A.; IVANOV, T.; D'ARCY, B.; MOSSEL, B.; VIT, P. Calidad de la miel de abejas y estándares de control: Revisión realizada por La Comisión Internacional de la Miel. 2001. Disponível em: $<$ http://www.beekeeping.com/articulos/calidad_miel.htm>. Acesso em 25 março de 2017.

BRASIL. Ministério da Agricultura, Pecuária e Abastecimento (MAPA). Instrução Normativa $\mathrm{n}^{\mathrm{o}} 11$, de 20 de outubro de 2000. Regulamento técnico de identidade e qualidade do mel. Diário Oficial da União, Seção 1, p. 16-17. 23/10/2000. Disponível em: http://extranet.agricultura.gov.br/sislegis/action/detalhaAto.do?method=gravarAtoPDF $\&$ tipo $=I N M \&$ numeroAto $=00000011 \&$ seqAto $=000 \&$ valorAno $=2000 \&$ orgao $=$ MAA\&co dTipo $=\&$ desItem $=\&$ desItemFim $=$. Acessado em 25 março de 2017.

CAMPOS, G.; DELLA-MODESTA, R. C.; SILVA, T. J. P.; BAPTISTA, K. E.; GOMIDES, M. F.; GODOY, R. L. Classificação do mel em floral ou mel de melato. Ciênc. Tecnol. Aliment., Campinas, v.23, n.1, p.1-5, 2003.

CASADO, P. S.; VIEIRA, G. H. C. Características físico-químicas de méis produzidos em Chapadão do Sul, estado do Mato Grosso do Sul, Brasil. Anais do Seminário de Extensão Universitária SEMEX, 2011.

FRANCO, B.D.G.M.; LANDGRAF, M. Microbiologia dos Alimentos. São Paulo:Atheneu, 2008. $182 \mathrm{p}$

IBGE. Diretoria de Pesquisas, Coordenação de Agropecuária, Pesquisa da Pecuária Municipal 2012. Disponível em: ftp://ftp.ibge.gov.br/Producao_Pecuaria /Producao_da_Pecuaria _Municipal/2012/tabelas_pdf/tab08.pdf. Acessado em 25 março de 2017.

OLAITAN, P. B.; ADELEKE, O. E.; OLA, I. O. Honey: a reservoir for microorganisms and an inhibitory agent for microbes. African Health Sciences, v.7, p.159-165. 2007. Disponível em: <http://www.ncbi.nlm.nih.gov/pmc/articles /PMC2269 714/pdf /AF HS0703-0159.pdf>. Acesso em 25 março de 2017.

SILVA, N.; JUNQUEIRA, V. C. A.; SILVEIRA, N. F. A.; TANIWAKI, M. H.; SANTOS, R. F. S.; GOMES, R. A. R. Manual de métodos de análise microbiológica de alimentos. 3ed. São Paulo: Livraria Varela, 552p. 2007.

SNOWDON, J. A.; CLIVER, D. O. Microorganisms in honey. Int. J. Food Microbiol., v.31, p.1-26. 1996.

TAORMINA, P. J.; NIEMIRA, B. A.; BEUCHAT, L. R. Inhibitory activity of honey against foodborne pathogens as influenced by the presence of hydrogen peroxide and level of antioxidant power. Int. J. Food Microbiol., v.69, p.217-225. 2001.

ZENEBON, O.; PASCUET, N. S.; TIGLEA, P. Métodos físico-químicos para análise de alimentos. Instituto Adolfo Lutz (São Paulo). 1020 p. 2008. Versão eletrônica. Disponível em: http://www.ial.sp.gov.br. Acessado em 25 de março de 2017. 